\title{
¿Genes, células, áreas da inteligência cerebral e sociedade com inteligência prejudicada, o que tudo isso tem em comum?
}

\author{
Dr. Fabiano de Abreu Agrela Rodrigues ${ }^{1}$ \\ deabreu.fabiano@gmail.com
}

\section{RESUMO}

A inteligência humana pode ser considerada uma conquista evolutiva. Ela é expressão máxima do desenvolvimento humano, diferenciando os homens dos outros animais. Sua definição é ampla e depende de vários elementos para a sua formação e desenvolvimento, assim como para o seu retrocesso ao longo dos anos em nossa sociedade. O presente artigo tem como objetivo abordar o papel fundamental da hereditariedade, genética e do córtex cerebral na formação da inteligência e as causas para o seu declínio.

Palavras-Chaves: inteligência; córtex; genes; sociedade.

\footnotetext{
${ }^{1} \mathrm{PhD}$, neurocientista, mestre psicanalista, biólogo, historiador, antropólogo, com formações também em neuropsicologia, psicologia, neurolinguística, neuroplasticidade, inteligência artificial, neurociência aplicada à aprendizagem, filosofia, jornalismo e formação profissional em nutrição clínica - Diretor do Centro de Pesquisas e Análises Heráclito; Chefe do Departamento de Ciências e Tecnologia da Logos University International, UniLogos; Membro da Federação Européia de Neurociências e da Sociedade Brasileira e Portuguesa de Neurociências. Universidades em destaque: Logos University International, UniLogos, Nova de Lisboa, Faveni, edX Harvard, Universidad de Madrid.
} 


\title{
¿Genes, cells, areas of brain intelligence and society with impaired intelligence, what do all these have in common?
}

\begin{abstract}
Human intelligence can be considered an evolutionary achievement. It is the highest expression of human development, differentiating men from other animals. Its definition is broad and depends on several elements for its formation and development, as well as for its regression along the years in our society. The present article aims to approach the fundamental role of heredity, genetics and the cerebral cortex in the formation of intelligence and the causes for its decline.
\end{abstract}

Keywords: intelligence; cortex; genes; society.

Artículo recibido: 05 octubre. 2021 Aceptado para publicación: 02 noviembre 2021 Correspondencia: deabreu.fabiano@gmail.com

Conflictos de Interés: Ninguna que declarar 
Genes, células, áreas da inteligência...

\section{INTRODUÇÃO}

A inteligência é geralmente definida como a capacidade de utilizar funções cognitivas de forma extensiva e bem aplicada para resolver problemas, racionalizar dilemas, escolher melhores caminhos e alternativas para situações importantes, reter informações, desenvolver conhecimentos em determinadas áreas, se adaptar a diferentes ambientes, fazer conexões entres saberes diversos, lidar com pessoas e entender seus comportamentos,

Tais funções cognitivas como a memória e o raciocínio lógico são desenvolvidas em diferentes áreas do cérebro e tem como principais determinantes hereditariedade e a estrutura do córtex cerebral. Esse processo de desenvolvimento pode ser observado pela lente da evolução humana, que permitiu o acréscimo de diferentes habilidades e mudanças cerebrais e físicas significativas entre gerações, passando de uma espécie hominídea para a outra.

As informações importantes passadas pelos homens para os seus descendentes estão contidas no gene humano. O gene é uma unidade fundamental no nosso DNA, ele permite que os filhos herdem características importantes dos seus pais como traços físicos, alguns traços de personalidade, doenças hereditárias e a inteligência, sendo esta estudada desde o início do século vinte por diversas teorias que utilizam, cada uma em sua área, diferentes fatores como determinantes para a sua formação e desenvolvimento, assim como as possíveis razões para o seu declínio (Deary, 2021).

Observando o nível educacional atual e os resultados obtidos em testes e provas, é possível perceber uma diminuição de habilidades fundamentais e expressivas da inteligência como raciocínio lógico, retenção de conhecimento, fluência na leitura e boa escrita. Essa diminuição muitas vezes está relacionada e é ocasionada por diversos fatores com a incapacidade dos neurônios de produzir sinapses, ou seja, se "comunicarem" uns com os outros e levar informações essenciais para as diferentes áreas do cérebro responsáveis pela memória, aprendizagem e funções motoras. Esse fenômeno é conhecido com neuroplasticidade e tem a capacidade de provocar mudanças significativas na estrutura cerebral, influenciando e melhorando funções cognitivas dos indivíduos (Demarin et al, 2014).

Por essa razão, é importante entender quais e como se comportam os determinantes neurobiológicos que influenciam na formação da inteligência permitindo o avanço dos 
estudos na área, a intervenção durante processos de aprendizagens que não apresentam resultados concretos e o aperfeiçoamento das metodologias educacionais com novas descobertas e dados.

\section{BASE NEUROBIOLÓGICA DA INTELIGÊNCIA HUMANA}

Qual é a base neurobiológica da inteligência humana? Os cérebros de algumas pessoas são mais eficientes do que de outras e o comportamento tem relação com a inteligência, portanto, compreender os fundamentos biológicos dessas diferenças é cada vez mais necessário para trazer a tão necessária homeostase que o organismo precisa para seu bom funcionamento. Assim como comportamentos que não tragam prejuízos sociais e individuais.

A evolução da nossa espécie tornou-se significativa pelo lobo frontal, exatamente a região responsável pela tomada de decisões, prevenção, processamento de informações, funções motoras, regulação das emoções, processos executivos, cognição e da lógica. O lobo frontal ocupa um terço do total da área do córtex e se localiza na parte anterior do encéfalo ocupando todo o córtex cerebral a partir do sulco central (Carroll, 1993).

O emaranhado de neurônios e células gliais de enorme complexidade são a resposta para a inteligência que determina o nosso comportamento. Logo, compreender atitudes como impulsividade, incoerência, falta de percepção, falta de empatia, falta de prevenção sobre as consequências da atitude, entre outras ações pejorativas, como lógico, cabe estudar a inteligência localizada como precursora no lobo frontal. Chamo de precursora com base na "Inteligência DWRI" onde comprovo através de estudos que o raciocínio lógico, vinculado à tomada de decisões e a coerência, dita o desenvolvimento cognitivo de todas as regiões relacionadas ao intelecto humano (Rodrigues, 2021).

Testes de QI e estudos de imagem cerebral investigam a estrutura e a função macroscópicas do cérebro para identificar áreas cerebrais envolvidas na inteligência, também os estudos de associações genéticas visam identificar genes e loci genéticos associados à inteligência.

A inteligência humana é um dos traços comportamentais mais hereditários, estudos com gêmeos apontaram uma faixa de $50 \%$ a $80 \%$, chegando a $86 \%$ para QI verbal. Uma metanálise de 88 estudos com mais de 8.00 indivíduos da relação entre volume cerebral in vivo e inteligência encontrou uma correlação positiva moderada, mas significativa, menor que 0,24. Ou seja, o volume cerebral está associado a uma maior inteligência 
mesmo com medidas pouco significantes, mas o tamanho não se torna determinante já que há casos de maior tamanho e menor QI, assim como QI alto e menor tamanho em comparação a outros de maior QI (Pietschnig, 2015).

Estudos de imagens, morfometria baseada em voxels (VBM), associadas a estruturas de indivíduos de alto escores de QI, mostraram um padrão amplamente distribuídos correlacionados com o volume craniano nas regiões do lobo frontal, lobo temporal, lobo parietal, hipocampal e cerebelar. Estrutura das áreas frontais de Brodmann 10, 45-47, área orbitofrontal, as áreas parietais 39 e 40 e a área temporal 21, lobo temporal - giro temporal inferior e médio, córtex parahipocampal e córtex de associação auditiva contribuem positivamente para os escores de QI (Jung, 2007).

O volume da matéria cinzenta muda ao longo da infância e na fase adulta, influenciado pelos hormônios, neurotransmissores, aprendizagem e experiência, de acordo com a plasticidade cerebral. Mudanças estruturais transitórias e seletivas com rearranjos de dendritos e sinapses entre os neurônios são significativas na espessura do córtex. Crianças com alto QI demonstram um córtex particularmente plástico com a fase inicial acelerada e prolongada de aumento e afinamento cortical, ou seja, início e término por um período mais prolongado e tem o afinamento natural do córtex mais tardio (Narr et al, 2017).

Sobre os tipos de inteligência, essas são determinadas pela tomada de decisões a desenvolver regiões do cérebro de acordo com o tipo de inteligência. Distinguidos na psicologia, a inteligência cristalizada está relacionada ao conhecimento e experiências anteriores a refletir a cognição verbal, enquanto a inteligência fluída requer raciocínio adaptativo em novas situações.

Estudos indicam que a inteligência fluida esta relacionada à função e estrutura das regiões do lobo frontal, depende de uma função mais eficiente das áreas corticais distribuídas como o córtex frontal lateral estabelecido no raciocínio, atenção e memória de trabalho. As medições do volume de substância cinzenta de duas áreas frontais - córtices orbitofrontais (OFC) e cingulados anteriores rostrais (rACC) - foram complementadas pela conectividade da substância branca entre essas regiões. O córtex pré-frontal, estrutura, função e conectividade se relacionam com inteligência geral.

Já a inteligência cristalizada depende de estruturas e espessura corticais em áreas laterais dos lobos temporais. Áreas parietais (área de Brodman 40) mostram sobreposição em seu envolvimento em inteligência cristalizada e outros tipos de inteligência, a área temporal 
de Brodman 38 está exclusivamente envolvida na inteligência cristalizada. Isso deixa entendido a relação semântica de distintas regiões cerebrais, assim como a relação do lobo temporal com as emoções e o armazenamento da memória (Brown, 2016).

A inteligência g de Spearman, seria mais bem subdividida em inteligência fluida e cristalizada, como referência a compreensão verbal, memória de trabalho, velocidade de processamento e organização perceptiva, resultando assim em um mapa definido das regiões corticais no hemisfério esquerdo e direito (Duncan, 2000).

A substância branca consiste em axônios mielinizados que transferem informações de uma região do cérebro a outra e a integridade dos tratos da substância branca é essencial para a função cognitiva. Pacientes com retardo mental, por exemplo, apresentam danos na integridade dos tratos da substância branca, proeminente no fascículo uncinado direito que conecta partes do lobo temporal com as áreas do lobo frontal (Penke et al, 2018).

A inteligência geral tem relação com uma menor integridade do trato da substância branca exercendo um efeito negativo substancial através da redução da velocidade de processamento de informações. Fibras axonais estruturalmente intactas fornecem a infraestrutura neuroanatômica para processamento rápido de informações dentro de redes cerebrais generalizadas, apoiando a inteligência geral (Yu et al, 2008).

Sobre a genética, a herdabilidade da inteligência tem maior influência nos lobos frontal e temporal, estudos de associação genômica ampla (GWAS) comprovaram que o nível e tempo educacionais tem influência fenotípica e genética. A associação genética de inteligência identificou 206 loci genômicos e implicou 1.041 genes, adicionando 191 novos loci e 963 novos genes aos anteriormente associados à capacidade cognitiva (Lam, 2017).

A maioria dos genes associados à inteligência estão implicados no desenvolvimento prénatal, com alguns genes essenciais para a função sináptica e plasticidade ao longo da vida útil. O peso e comprimento ao nascer apresentam relações poligênicas com a longevidade e desempenho cognitivo. Neurônios das regiões hipocampal, cortical mesencéfalo e cortical frontal estão relacionadas aos genes da inteligência. Há um enriquecimento significativo de genes associados dentro de neurônios piramidais na área hipocampal CA1 e regiões somatossensoriais corticais. Os neurônios piramidais são mais abundantes no neocórtex e no hipocampo, estruturas associadas a funções executivas superiores, tomada de decisão, resolução de problemas e memória (Andreasen, 1993). 
Sobre os neurônios, pessoas com escores de QI mais alto apresentam maior espessura cortical, com neurônios maiores capazes de processar entradas sinápticas com maior precisão e potenciais de ação mais rápidos em células maiores. Registros revelam que neurônios piramidais desses indivíduos são capazes de sustentar potenciais de ação rápidos durante a atividade neuronal, recebem mais entradas sinápticas sendo capazes de alcançar maior resolução da integração sináptica processando essas múltiplas entradas sinápticas separadamente e simultaneamente, retransmitindo essas múltiplas entradas para a saída. Dendritos maiores contêm fisicamente mais contatos sinápticos e processar mais informações. O gene FOXO3 (associado à longevidade) faz parte da via de sinalização do fator de crescimento semelhante à insulina, níveis de IGF-1(fator de crescimento tipo insulina I) estão relacionados aos dendritos e consequentemente à cognição (Goriounova et al, 2018).

\section{CONSIDERAÇÕES FINAIS}

Avaliando as perspectivas relacionadas ao comportamento atual em nossa sociedade, já decretado défices na memória, atenção e comportamentos pejorativos como determinado no início do texto. Concluí-se que os comportamentos têm relação com prejuízos na região frontal do cérebro e sua comunicação com a região temporal. Que a inteligência é um fator crucial para evitar esses prejuízos e que a educação se faz necessária para a plasticidade cerebral como desenvolvimento das regiões cerebrais relacionadas à inteligência.

Este processo do déficit ocorre já que a ansiedade, como uma pendência, tende a buscar através da amígdala cerebral um mapa de memórias negativas para que possa "safar" da situação de perigo. Logo, também de forma instintiva, a mesma ansiedade pede a liberação de dopamina para buscar um linear de equilíbrio que o tire da zona de "perigo" e traga boas sensações. A questão é que o organismo tende a buscar mais boas sensações já que este linear não é absoluto, ou seja, não há uma homeostase permanente e sim uma oscilação de sensações em busca do linear ou de ultrapassá-lo.

Em diversos artigos descrevo os prejuízos no cérebro no mau uso da internet e sua relação com o excesso de ansiedade. Assim como as consequências dos derivados da ansiedade causando doenças como depressão, transtornos, síndromes e comportamentos prejudiciais e a relação com a espessura das regiões do cérebro relacionado à emoção e raciocínio. 


\section{REFERÊNCIAS}

Andreasen, N. C., Flaum, M., Swayze, V. II., O'Leary, D. S., Alliger, R., Cohen, G., et al. (1993). Inteligência e estrutura cerebral em indivíduos normais. Estou. J. Psiquiatria 150, 130-134. doi: 10.1176/ajp.150.1.130

Brown, R. E. (2016). Hebb and Cattell: the genesis of the theory of fluid and crystallized intelligence. Frontiers in Human Neuroscience, 10, 606.

Carroll, J. B. (1993). Habilidades Cognitivas Humanas: Uma Pesquisa de Estudos Fatores Analíticos. Nova York, NY: Cambridge University Press

Deary, I. J., Cox, S. R., \& Hill, W. D. (2021). Genetic variation, brain, and intelligence differences. Molecular Psychiatry, 1-19.

Demarin, V., \& MOROVIĆ, S. (2014). Neuroplasticity. Periodicum biologorum, 116(2), 209-211.

Dicke, U., \& Roth, G. (2016). Neuronal factors determining high intelligence. Philosophical Transactions of the Royal Society B: Biological Sciences, 371(1685), 20150180.

Duncan, J., Seitz, R. J., Kolodny, J., Bor, D., Herzog, H., Ahmed, A., et al. (2000). Uma base neural para inteligência geral. Ciência 289, 457-460. doi: $10.1126 /$ science.289.5478.457

Goriounova, N. A., Heyer, D. B., Wilbers, R., Verhoog, M. B., Giugliano, M., Verbista, C., et al. (2018). Neurônios piramidais humanos grandes e rápidos se associam à inteligência. Elife 7:e41714. doi: 10.7554/elife.41714

Jung, R. E., e Haier, R. J. (2007). A teoria da integração parietofrontal (P-FIT) da inteligência: evidências convergentes de neuroimagem. Comportamento. Brain Sci. 30, 135-154; discussão 154-187. doi: 10.1017/s0140525x07001185

Lam, M., Trampush, J. W., Yu, J., Knowles, E., Davies, G., Liewald, D. C., et al. (2017). Metanálise cognitiva GWAS em larga escala revela expressão neural tecidual específica e potenciais alvos de drogas nootrópicas. Representante de Células 21, 2597-2613. doi: 10.1016/j.celrep.2017.11.028

Narr, K. L., Woods, R. P., Thompson, P. M., Szeszko, P., Robinson, D., Dimtcheva, T., et al. (2007). Relações entre QI e espessura da substância cinzenta cortical regional em adultos saudáveis. Cereb. Cortex 17, 2163-2171. doi: $10.1093 /$ cercor/bhl125 
Genes, células, áreas da inteligência...

Penke, L., Maniega, S. M., Bastin, M. E., Valdés Hernández, M. C., Murray, C., Royle, N. A., et al. (2012). Integridade do trato da substância branca cerebral como base neural para a inteligência geral. Mol. Psiquiatria 17, 1026-1030. doi: 10.1038/mp.2012.66

Pietschnig, J., Penke, L., Wicherts, J. M., Zeiler, M. e Voracek, M. (2015). Metanálise de associações entre o volume cerebral humano e as diferenças de inteligência: quão fortes elas são e o que elas significam? Neurosci. Biocomportamento. Rev. 57, 411-432. doi: 10.1016/j.neubiorev.2015.09.017

Plomin, R., \& Spinath, F. M. (2004). Intelligence: genetics, genes, and genomics. Journal of personality and social psychology, 86(1), 112.

Posthuma, D., de Geus, E. J., e Boomsma, D. Eu. (2001). A velocidade perceptivoauditiva e o QI estão associados através de fatores genéticos comuns. Comportamento. Genet. 31, 593-602. doi: 10.1023/A:1013349512683

RODRIGUES, F. Dwri Intelligence And Other Intelligences. International Journal of Development Research, 11(1), 43576-43584.

Roth, G. (2015). Convergent evolution of complex brains and high intelligence. Philosophical Transactions of the Royal Society B: Biological Sciences, 370(1684), 20150049.

Savage, J. E., Jansen, P. R., Stringer, S., Watanabe, K., Bryois, J., de Leeuw, C. A., et al. (2018). Metanálise de associação genômica ampla em 269.867 indivíduos identifica novos vínculos genéticos e funcionais com a inteligência. Nat. Genet. 50, 912-919. doi: 10.1038/s41588-018-0152-6

Shaw, P., Greenstein, D., Lerch, J., Clasen, L., Lenroot, R., Gogtay, N., et al. (2006). Habilidade intelectual e desenvolvimento cortical em crianças e adolescentes. Natureza 440, 676-679. doi: 10.1038/nature04513

Yu, C., Li, J., Liu, Y., Qin, W., Li, Y., Shu, N., et al. (2008). Integridade e inteligência do trato da substância branca em pacientes com retardo mental e adultos saudáveis. Neuroimagem 40, 1533-1541. doi:

10.1016/j.neuroimage.2008.01.063 